\title{
Rapid Source Estimation from Global Calibrated Paths
}

\section{Sidao Ni, ${ }^{1}$ Don Helmberger, ${ }^{2}$ and Arben Pitarka ${ }^{3}$}

\section{INTRODUCTION}

On 9 October 2006, an explosion occurred in North Korea as predicted by that country's press office (Figure 1). The highfrequency $P$ waves relative to $S$ waves allowed easy identification (Richards and Kim 2007a, 2007b). However, estimating the yield of the explosion proved more difficult. Richards and Kim (2007a, 2007b ) employed the current procedure for estimating the size of events from inferences from magnitude-yield curves, usually $m_{b}$ or a regional proxy, $m_{b}\left(L_{g}\right)$. Linear plots of $m_{b}$ vs. yield are based on measured $m_{b}$ for known yields, i.e., Amchitka and Nevada Test Site (NTS), etc. In this particular case, they used Murphy's (1977) formula, which states $m_{b}=4.75+\log Y$, where the initial amplitudes of short-period (SP) $P$ waves at a large number of azimuthally distributed measurements are made. The same $m_{b}$ measure is used for earthquakes where it is assumed that by this averaging, we can eliminate radiation pattern effects, since the amplitudes can vary by a factor of 10 (Butler and Ruff 1980). However, the radiation patterns of down-going energy are distinctly different between strike-slip and dip-slip mechanisms. The former are weak at ray parameters emitting $P$ waves teleseismically. Thus one would expect $m_{b}$ is to be biased low for strike-slip events if only distance $P$ waves are available. This observation has been noted in Zhu et al. (2006) where regionally determined $M_{w}$ is compared with published $m_{b}$. Thus, we expect smaller $m_{b}$ from strike-slip events of about 0.4 magnitudes based on the above study. This feature can be observed directly (Figure 2) by examining the various mechanisms given in Figure 1. Note that the strikeslip event $\left(M_{w}=4.5\right)$ is relatively weak at the ILAR array, at least at the start. If one measures the $P$-wave amplitude at the predicted time of arrival, one would obtain a very small $m_{b}$. The actual arrival in this case is late, according to the National Earthquake Information Center (NEIC) report. Modern seismology has greatly improved with excellent instrument calibration, and mapping out travel times has similarly improved with the source specific station corrections (SSSC) methodology (Yang et al. 2001). Thus, the alignment given in Figure 2

1. Mengcheng National Geophysical Observatory, University of Science and Technology of China, Hefei, Anhui, China

2. California Institute of Technology, Pasadena, California

3. BAE Systems, Patrick AFB, Florida is probably more accurate. The thrust event has a clear arrival even though its amplitude has been reduced by a factor of five relative to the strike-slip event (top trace). The explosion and the 20040529 earthquake are five times smaller than the thrust event in amplitude, which reflects their smaller magnitudes. Since the ray paths between the neighboring events (explosion and earthquake 20020416) are similar, we will assume they

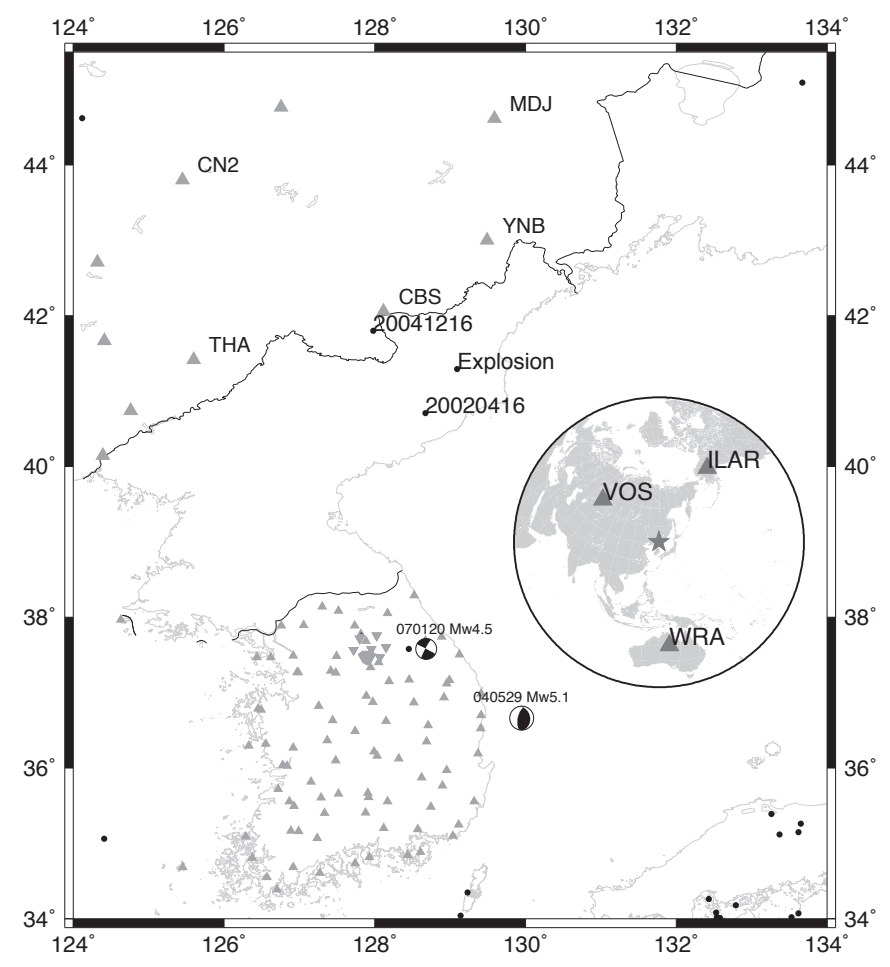

- Figure 1. Stations and events $(\mathbf{M}>4)$ in the Korean Peninsula and adjacent regions. Triangles indicate broadband and shortperiod stations of the China Seismic Network and Korean Seismic Network, and the inverted triangles indicate IMS stations (KSRS). Source mechanisms of event 070120 and 020416 are determined by the CAP ("cut and paste") method, while the source mechanism of event 040529 (strike/193/dip/62/rake101) is from Hermann et al. (2005). Dots indicate earthquakes $>m_{b} 4.0$ and explosions according to NEIC and China Earthquake Administration catalogs from 2001 to 2007. The inset shows teleseismic stations (VOS, ILAR, and WRA) used in this study. 

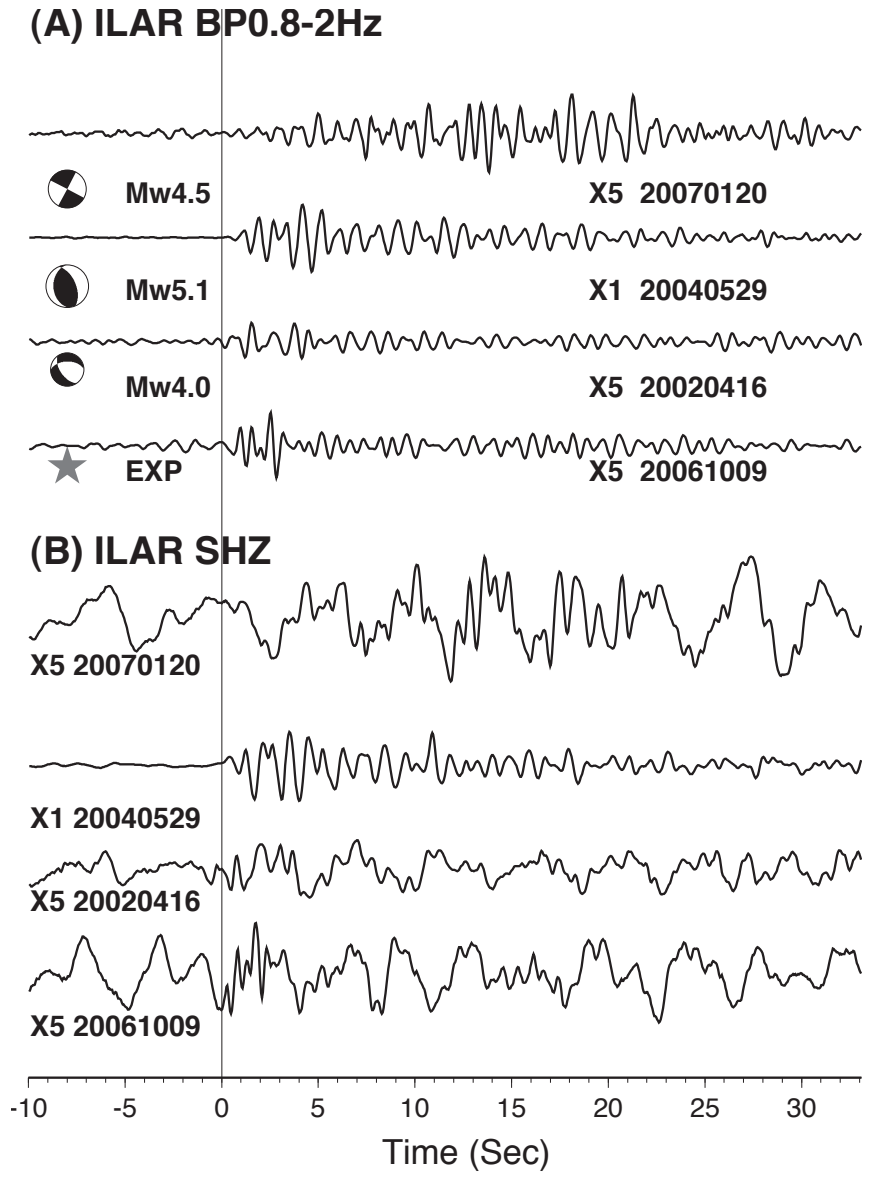

$\Delta$ Figure 2. Comparison of stacked records from the ILAR array filtered to short periods in A) and broadband in B). The top traces are for the strike-slip event $M_{w}=4.5$, the second from the thrust event $M_{w}=5.1$, the third trace from the normal event near the test site $\left(M_{w}=4.0\right)$, and the bottom trace from the NK explosion. The amplitude scale has been reduced by five for the thrust event $(M w=5.1)$ relative to the other four.

are the same for $P$ and use the earthquake to calibrate the path in terms of attenuation and station correction. First we need accurate source descriptions of the earthquakes from regional modeling. Next, we will use these teleseismic path calibrations to estimate the yields by inverting the waveform data.

\section{PATH CALIBRATION}

It is well known that the amplitude of short-period teleseismic $P$ waves can be different from theoretical prediction by a factor of 10 (Butler and Ruff 1980), which could be due to a focusing and defocusing effect due to small-scale 3-D velocity structure or a large variation of mantle attenuation $\left(t^{*}\right)$. Short-period $P$ waves also show substantial amplitude variation at local distances (Tan and Helmberger 2007), but they are found to be mostly station side effects. Tan and Helmberger (2007) proposed a calibrating scheme to retrieve true $P$ amplitude with amplitude adjustment factor (AAF), which is basically the amplitude ration between observed $P$ wave and synthetic $P$
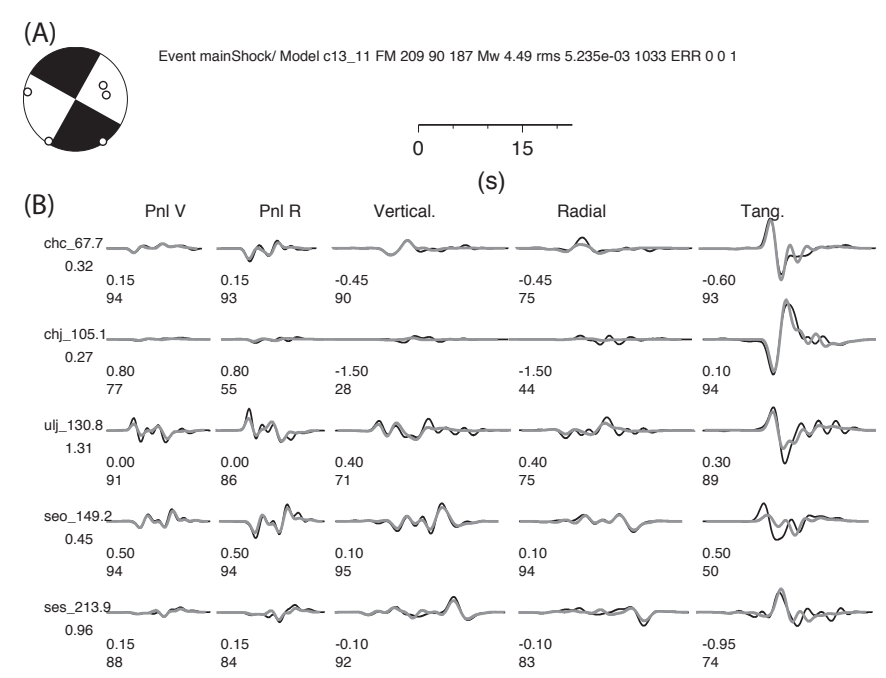

A Figure 3. A) CAP modeling of the Pnl and surface waves for the 070120 event in South Korea. Pnl waves are filtered with bandpass $(0.02-0.5 \mathrm{~Hz})$ and the surface waves are filtered with $(0.01-0.4 \mathrm{~Hz})$. Black thin traces show observed seismogram and gray thick lines are synthetic seismograms. The event occurred at a depth of $11 \mathrm{~km}$, with an almost pure strike-slip mechanism. CAP is usually applied with a bandpass filter of $0.02-0.3 \mathrm{~Hz}$ for $\mathrm{Pnl}$ and $0.01-0.1$ for surface waves, but we are able to achieve shorter period modeling because of relatively simple crustal structure in the Korean Peninsula and good station coverage. The distances in $\mathrm{km}$ are noted after the station names along with the $P$-timing correction. The numbers beneath the various waveform segments indicate the timing shifts and cross-correlations (cc's). B) Velocity model used for the CAP inversion is displayed in the bottom panel. This model is based on a seismic refraction survey (Cho et al. 2005), which reveals a mid-crustal discontinuity and moderately varying Moho.

wave for events with well-resolved mechanisms and moment. Here their calibration scheme is extended for the teleseismic case, as detailed in the following sections.

The strike-slip event (070120) in Figure 1 has been extensively studied broadband (BB) by Pitarka et al. (2008) for the full South Korean array. The results at the nearby regional stations are presented in Figure 3A, where the amplitudes are plotted multiplied by their distance dependence $(r)$ for $P_{n l}$ and $\left(r^{1 / 2}\right)$ for the surface waves. These fits are over the periods 2 to $20 \mathrm{~s}$ for $P_{n l}$ and 3 to $50 \mathrm{~s}$ for surface waves. Note that station chj is slightly off, but nodal stations are naturally downweighted in the CAP ("cut and paste") inversion ( Zhu and Helmberger 1996). When the arrivals are away from their nodes, they have cross-correlations over 0.9 with relatively small shifts. The model is presented in Figure 3B. The South Korean data is officially closed for the North Korea (NK) explosion, but the long-period KSRS array is part of the global International Monitoring System network. Thus, it is difficult to discuss the NK explosion in the open literature except at this array. The data for both the 020416 earthquake and NK explosion is displayed in Figure 4. Obviously, the explosion is very weak 
(A) Event $020416 \mathrm{EQ}$
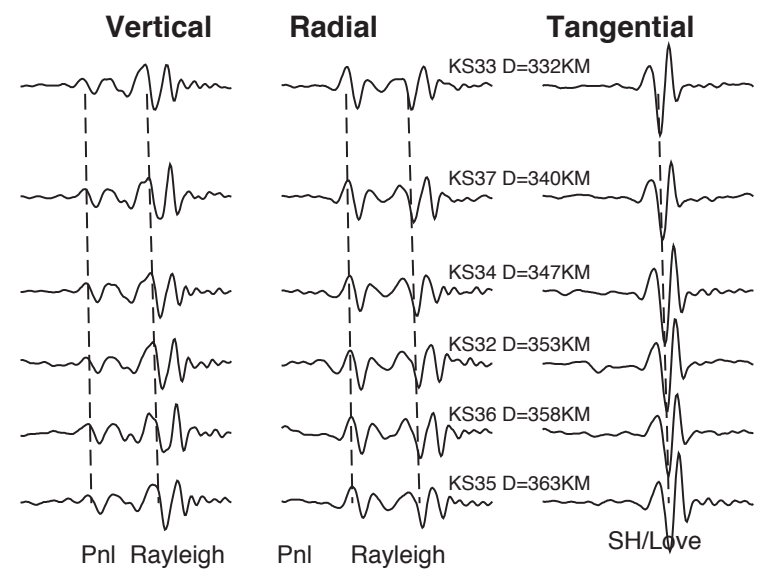

Pnl Rayleigh $\begin{array}{lllll}0 & 50 & 100 & 150 & 200\end{array}$

(B) Event $061009 \mathrm{EX}$

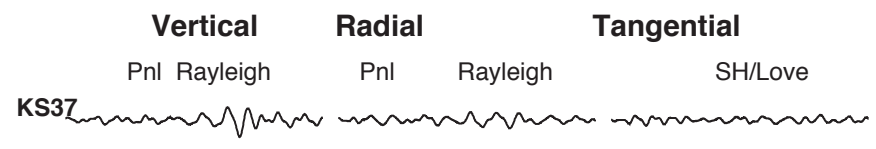

KS36

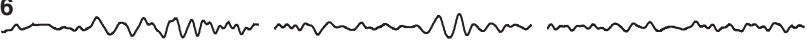

KS33

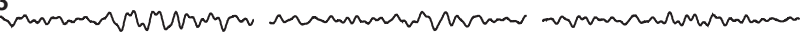

KS32

$0 \quad 50 \quad 100 \quad 150 \quad 200$

Time (sec)

A Figure 4. Comparison of three-component long-period (0.02$0.1 \mathrm{~Hz}$ ) seismograms for the event 020416 ( $A$, top) and the 061009 explosion (B, bottom) recorded by common stations KS32, 33, 36 , and 37. Pnl and Rayleigh waves are three-four times smaller for the explosion than those of the 020416 earthquake. Signalto-noise ratio (SNR) of Love waves for the explosion is low, if present at all, but the Rayleigh wave is clearly visible for the explosion.

in comparison with the earthquake, which is expected from the many $m_{b}: M_{S}$ reports. However, we could easily have a low-amplitude Rayleigh wave for an earthquake as for station chj in Figure 3. But the Love wave at this station is huge and distinctly unlike an explosion. Some of the discrimination methods use the ratio of short-period energy for the $P$-wave train divided by the sum of all three long-period components to separate the event populations, i.e., Helmberger and Woods (1996).

Determining an accurate $M_{S}$ or long-period (Rayleigh waves) for the explosion requires detailed efforts as displayed in Bonner et al. (2008) and Koper et al. (2008). Note that these reports were published two years after the event occurred because of the difficulties of acquiring local data. Their results indicate that the event has a small $M_{S}(2.9$ with a moment of $(3.1 \pm 0.7) \times 10^{14} \mathrm{Nm}$.
The long-period earthquake data in Figure $4 \mathrm{~A}$ is of excellent quality and easily modeled with the South Korean Green's functions as presented in Figure 5. Not only are the fits extraordinarily good, but their shifts are small, indicating the crustal model also is very good. Thus, we will use this crustal model (Figure 3) in the remainder of this paper to predict the teleseismic waveforms. Although the NK explosion can be identified on arrays globally, only a few are clearly above the background noise level as discussed in Koper et al. (2008). The observations (vertical component) with the clearest teleseismic signals are given in Figure 6, with the stacks of two arrays (ILAR and WRA) and the single station VOS.

Synthetics for earthquakes can be generated by assuming an earth model containing an attenuation operator $t^{*}$, i.e., Helmberger (1983). We assume a simple triangular time function of $0.3 \mathrm{~s}$ for the 020416 event and $0.5 \mathrm{~s}$ for the 070120 event (which is likely longer than the true durations) so that the events can be approximated by a point source (see Tan and Helmberger 2007). Two sets of synthetics are displayed, one with a $t^{*}=0.5$ and one with $t^{*}=0.8$. The predictions for the strike-slip event do not fit as well as for the normal event since the former has a stronger $s P$, which tends to be more unstable than $p P$ for large datasets (Ni et al. 2008). However, the calibration is on the direct $P$ wave, which appears quite stable for those observations with negligible noise. Without amplitude corrections, the synthetics are too weak, which indicates that these stations are abnormal. Amplitude differences between stations on a global scale are known to vary by over a factor of 10 , but if we restrict the azimuths to a few degrees, the amplitude patterns remain quite similar (Butler and Ruff 1980; Lynnes and Lay 1988). In our case, only those paths with the lowest attenuation will be above the noise so that the corrections are quite uniformly high as indicated. Changing $t^{*}$ produces a new set of values. The $t^{*}$ with the smallest corrections are for $t^{*}=.5$ where WRA $=1.13, \mathrm{VOS}=1.0$ and ILAR $=0.67$. Note that only the nodal synthetic for the strike-slip event is badly predicted. For the explosion, we assume the time-history given by

$$
\psi(t)=\psi_{\infty}\left[1-e^{k t}\left(1+(k t)+\frac{1}{2}(k t)^{2}-B(k t)^{3}\right)\right]
$$

where $k$ is related to corner frequency, $B$ is a constant controlling overshoot, and $\psi_{\infty}$ is source volume or strength, expressed in $\mathrm{m}^{3}$. The source strength can be directly related to $M_{0}=4 \pi \rho \alpha^{2} \psi_{\infty}$ with $\rho$ the density, $\alpha$ the $P$ velocity and $M_{0}$ expressed in ergs (see Helmberger and Hadley 1981) for details. Here we assumed $M_{0}=3.1 \times 10^{14} \mathrm{Nm}, k=50$ from spectral estimates based on regional phases and found a depth of $700 \mathrm{~m}$ for $B=1.0$, with the AAF corrections. The simple source model does not predict the later arrivals, which can be even stronger than $P$. Numerical modeling suggests that such features are caused by the irregular surface conditions just above the explosion, i.e., Pitarka et al. (2008). But such features are difficult to predict, so we concentrate on the initial $P$ waveform and assume a simple elastic $p P$. This assumption has proven quite effective modeling previous shots as discussed in the next section. 
(A)

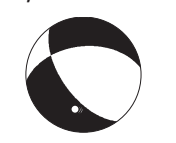

$$
\text { Even }
$$

Event

(B)

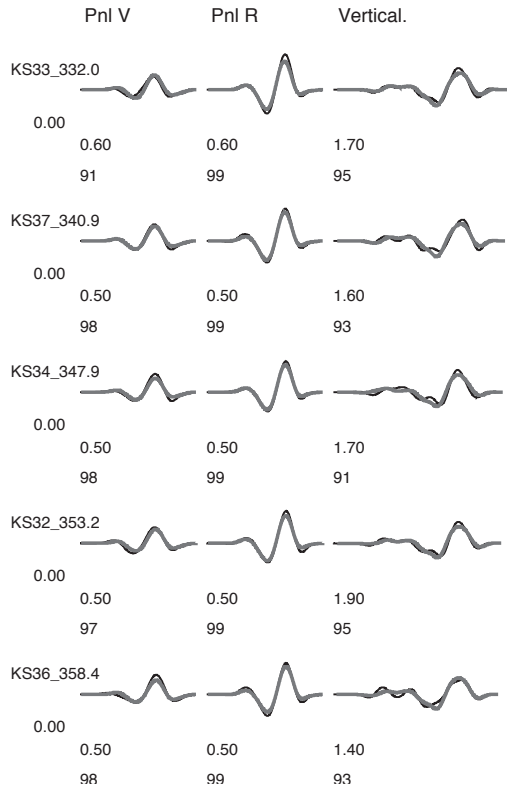

(C)

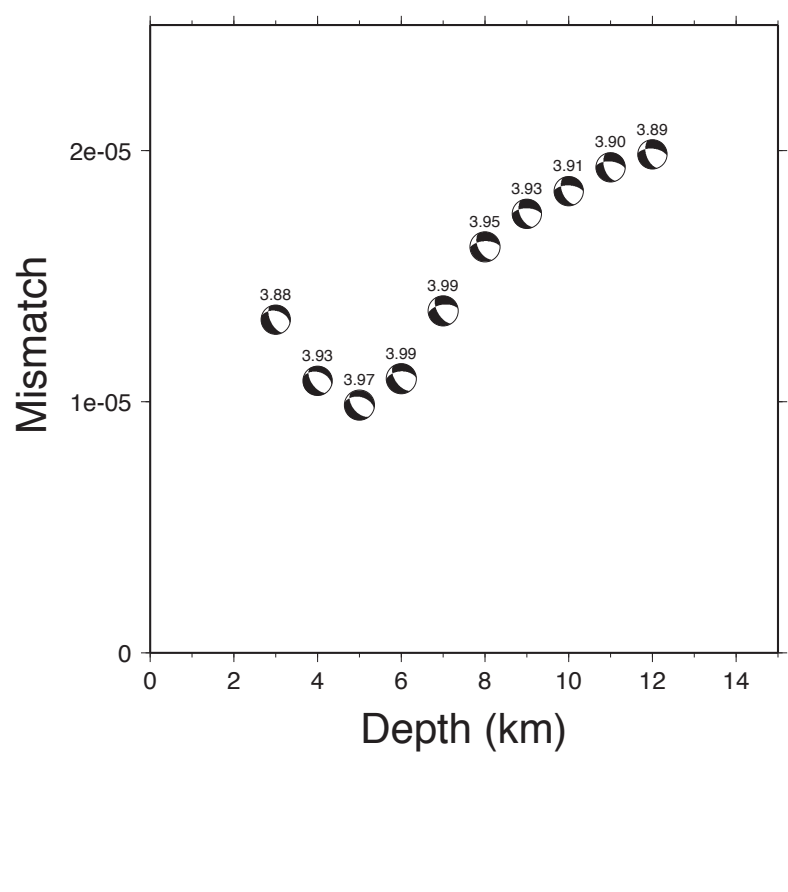

A Figure 5. A) CAP results of the 020416 event for the KSRS array data where the timing corrections are small and the cc's high. B) The preferred depth is $6 \mathrm{~km}$ with $M_{w}=4$. Adding other data did not change this solution substantially.
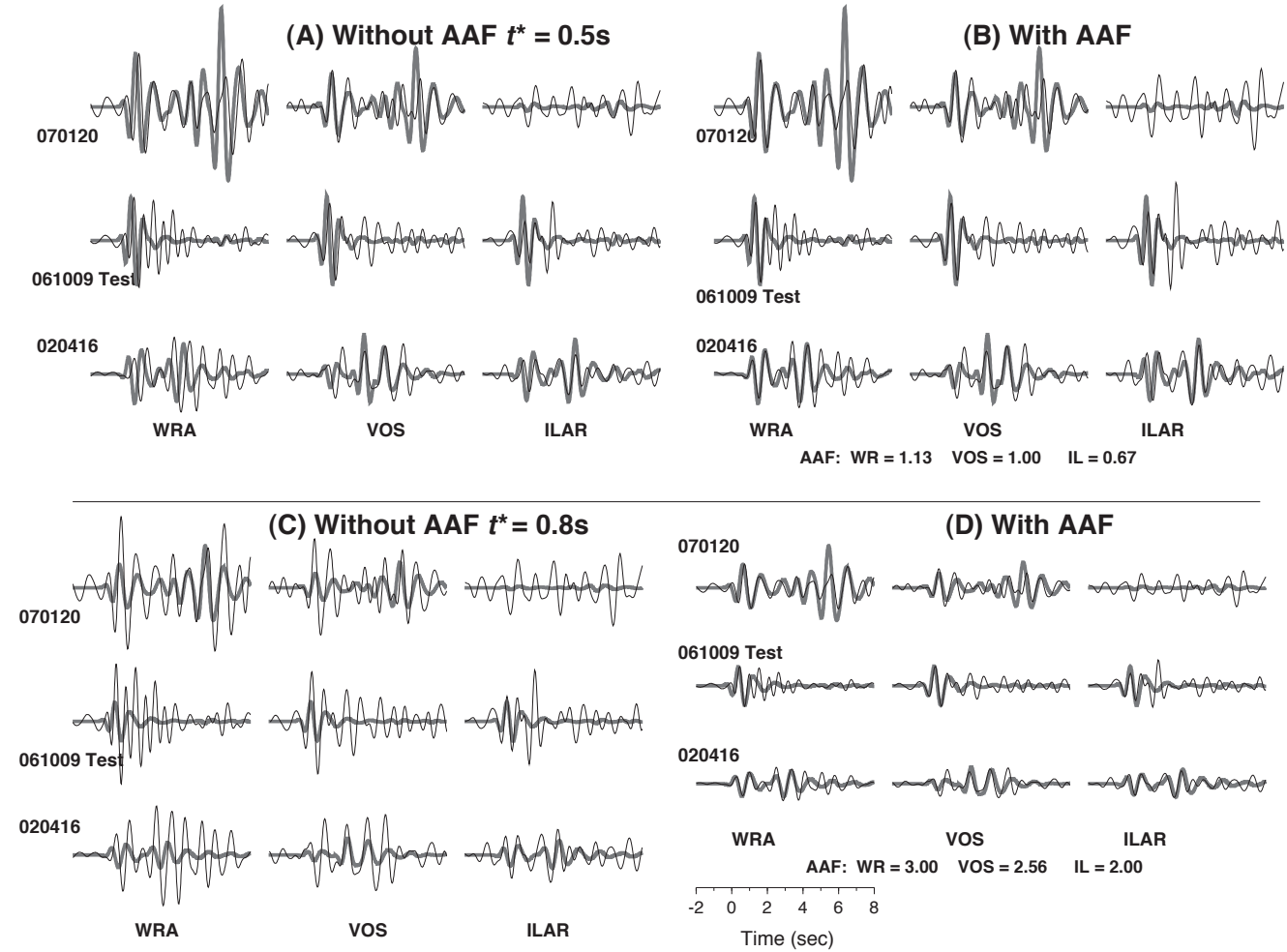

A Figure 6. Comparison of synthetic predictions (gray traces) and observations (black traces) for the strike-slip event (top traces), the normal event near the test (bottom traces), and the NK explosion in the middle. The synthetic amplitude depends on the $t^{*}$ with two cases, $0.5(A, B)$ and $0.8(C, D)$. A) and C) display comparisons before AAF is applied, while B) and D) after AAF applied. The AAFs are distinct for these two cases because different $t^{*}$ are used in computing synthetic seismograms. Seismograms in A) and B) are plotted with a common amplitude scale, while $\mathrm{C}$ ) and $\mathrm{D}$ ) are plotted in the same way as $\mathrm{A}$ and $\mathrm{B}$, but for $\mathrm{t}^{*}$ and different amplitude scales. 


\section{YIELD ESTIMATION FOR EXPLOSIONS}

Estimating yields $(Y)$ of underground nuclear explosions has a long history involving empirical relationships between $m_{b}: Y$ and $M_{S}: Y$ and, more recently, coda-magnitude: $Y$ as introduced earlier. Most of these strategies are discussed in Koper $e t$ al. (2008) and Bonner et al. (2008). The smallest yield is a $1 / 2 \mathrm{kt}$ derived by Walter et al. (2007) from regional spectra. The largest is that of Bonner et al. (2008), who suggested $4.5 \mathrm{kt}$ based on extensive analysis of surface waves.

We suggest still another method that is more in line with waveform modeling, using the $\psi(t)$ from Equation 1 but adding some scaling laws to estimate $\psi_{\infty}$ and $k$ directly from yield. Mueller and Murphy (1971) have derived scaling laws based on the physics of cavity pressure and size based on variation of yield, depth, and materials. Burdick et al. (1983) have simplified these to

$\psi_{\infty}=C_{1} Y / h^{0.27}$

with $Y$ in kt and $h$ in source depth in meters, and $C_{1}$ a constant for each test-site. The corner frequency

$k=C_{2} b^{0.42} / Y^{1 / 3}$

where $C_{2}$ is related to material properties, and ranges from about 6 for a very large explosion (Cannikin) to 40 for a smaller peaceful nuclear explosion (PNE) event (Rulison). These two constants have been studied extensively from nearby data, with

$C_{1}=12.3 \times 10^{8}$ and $C_{2}=4.7$ for Amchitka

and

$C_{1}=20 \times 10^{8}$ and $C_{2}=4.0$ for NTS.

See Saikia et al. (2001) for details.

Applying these to teleseismic data requires some assumption about attenuation in the upper mantle, and elastic behavior of $p P$ where spall is known to play an important role (Murphy 1977). How to interpret $m_{b}$, bias beneath test sites especially in the Soviet Union has been referred to as "The $t^{*}$ Wars" and not addressed here. In short, we will assume elastic behavior and the Amchitka scaling laws apply to the NK shot. The results are displayed in Figure 7, with the preferred yields forming a vertical strip between 0.5 and $2.5 \mathrm{kt}$. We assumed two $t^{*}$ calculations of 0.8 and 0.5 . Although the AAFs essentially remove the yield bias, they still affect the depth estimate by changing the high-frequency interference. We have included the surface wave moment estimate to produce our best estimates of yield ranging from 1.5 to $1.8 \mathrm{kt}$. While this manuscript was in review, a larger explosion occurred on 25 May 2009. We have used the same three stations to estimate its yield, which is included in Figure 9. We have also included a factor-of-six increase in moment based on the ratio of regional Rayleigh wave strength. The two best waveform fits are given

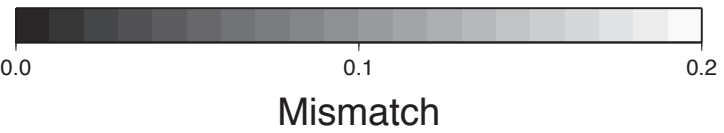

(A) $t^{\star}=0.8 \mathrm{~s}$
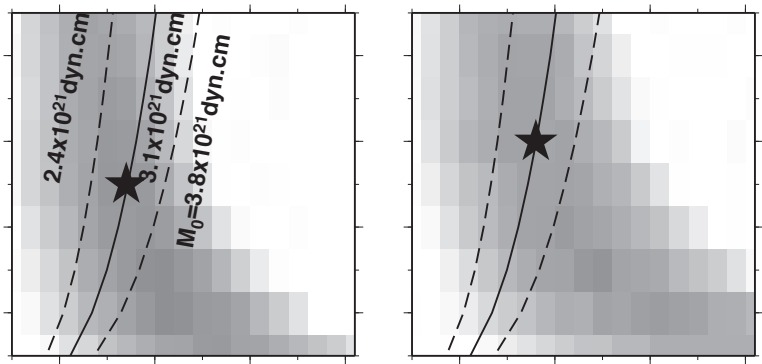

(B) $t^{\star}=0.5 s$
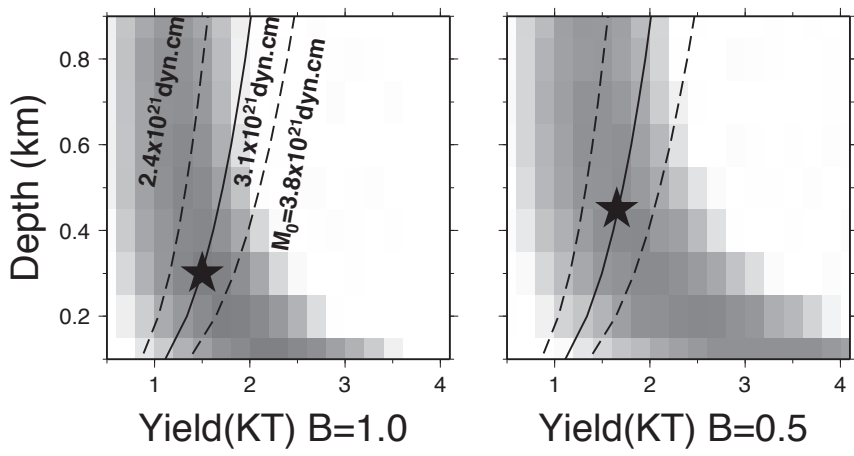

$\Delta$ Figure 7. Waveform mismatch can be calculated with $\left(M_{0}, \mathrm{k}\right)$ obtained from scaling law on yield and depth of burial. A) for $\left.t^{*}=0.8 \mathrm{~s}, \mathrm{~B}\right) t^{*}=0.5 \mathrm{~s}$. We search for optimal yield and depth for two different values of $B$. The curves are constant $M_{o}$ obtained from surface wave modeling (Bonner et al. 2008). The optimal mismatch and the constant $M_{o}$ curve show different trends; thus their intersection is probably the optimal estimate of yield and depth, as indicated by the stars. Yield is found to be within 1.5-2 $\mathrm{kt}$, depth within 300-500 m. Of course, uncertainty in scaling will make the error bound larger. Though AAF changes with different $t^{*}$, the estimate of yield and depth does not change much, arguing for robustness of calibration with earthquakes.

in Figures 8 and 10 for the first and second nuclear tests, respectively. The smaller $t^{*}$ suggests a shallow depth of burial of about $300 \mathrm{~m}$, which seems to be the overall most reasonable result.

We assumed elastic $p P$ in modeling the teleseismic waveforms, which is probably valid for small-yield contained tests. Therefore, our approach of constraining depth of burial from $P+p P$ is viable considering the previous successful estimation of depth for tests of much larger yield (Douglas and Marshall 1996). However, if the test was conducted in a horizontal tunnel underneath a mountain, the topographic effects might complicate teleseismic $p P$ waveforms, thus leading to some error in yield estimation. In Figure 6 , the signal about $2 \mathrm{~s}$ after $P$ wave appears on VOS, ILAR, and WRA stations for the nuclear test, arguing for its origin near the source side, and may be generated by $R g-P$ conversion due to drastic topography variation (Clouser and Langston 1995). In order to fully account for the 
(A)

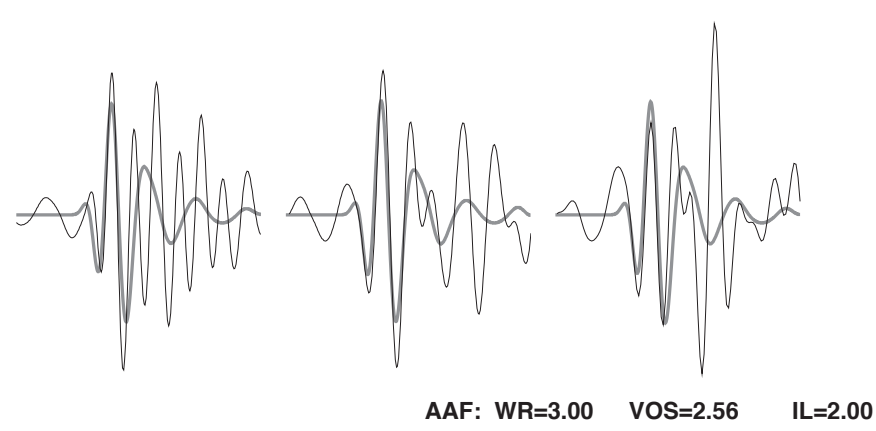

(B)

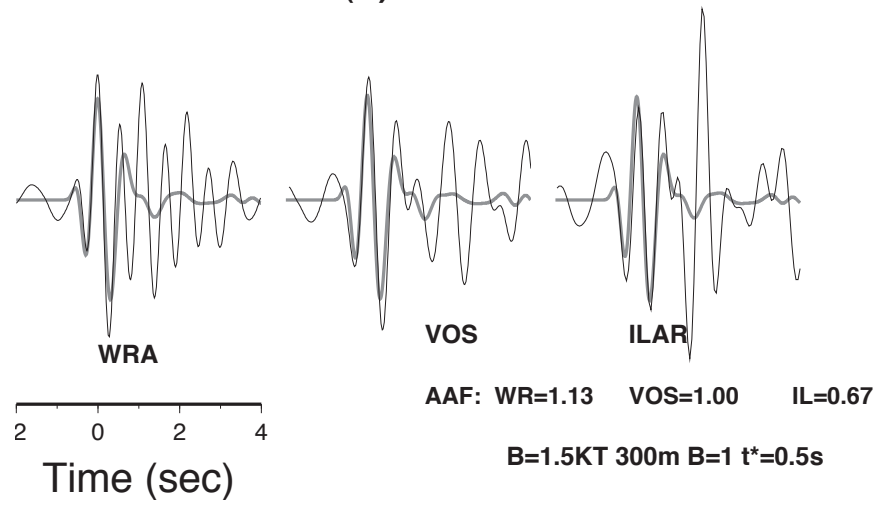

$\Delta$ Figure 8. Waveform fits obtained at the star locations in Figure 7 for $B=1$. A) $\left.t^{*}=0.8 \mathrm{~s}, \mathrm{~B}\right) t^{*}=0.5 \mathrm{~s}$.

topographic effects, 3D synthetic teleseismic waveforms would be helpful (Pitarka et al. 2008).

In conclusion, we have demonstrated how to calibrate paths to short-period arrays where stacking displays clear $P$-waveforms of small events $\left(M_{W} \sim 4\right)$, i.e., the North Korean test using the Amchitka scaling laws, which relate source strength and corner frequency $(k)$ to yields $(Y)$ for various depths of burial. We obtain a $Y$ of $1.5 \mathrm{kt}$ at a depth of 300 meters and $2 \mathrm{kt}$ at a depth of 600 meters for the two different $t^{*}$ values for the first event. A preliminary yield of $8 \mathrm{kt}$ at a depth of 400 meters is obtained for the second North Korea event. $\mathbf{<}$

\section{ACKNOWLEDGMENTS}

Waveform data was provided by the Incorporated Research Institutions for Seismology (IRIS). Supported by Chinese Academy of Science kzcx2-yw-116-01,NSFC,40537033 DOE Award \#DE-FC52-06NA27319, NSF Grant \#EAR-0337491. GPS contribution \#10045, Seismological Laboratory, Division of Geological and Planetary Sciences, California Institute of Technology.

\section{REFERENCES}

Bonner, J., R. B. Hermann, D. Harkrider, and M. Pasyanos (2008). The surface wave magnitude for the 9 October 2006 North Korean nuclear explosion. Bulletin of the Seismological Society of America 98 (5), 2,498-2,506.
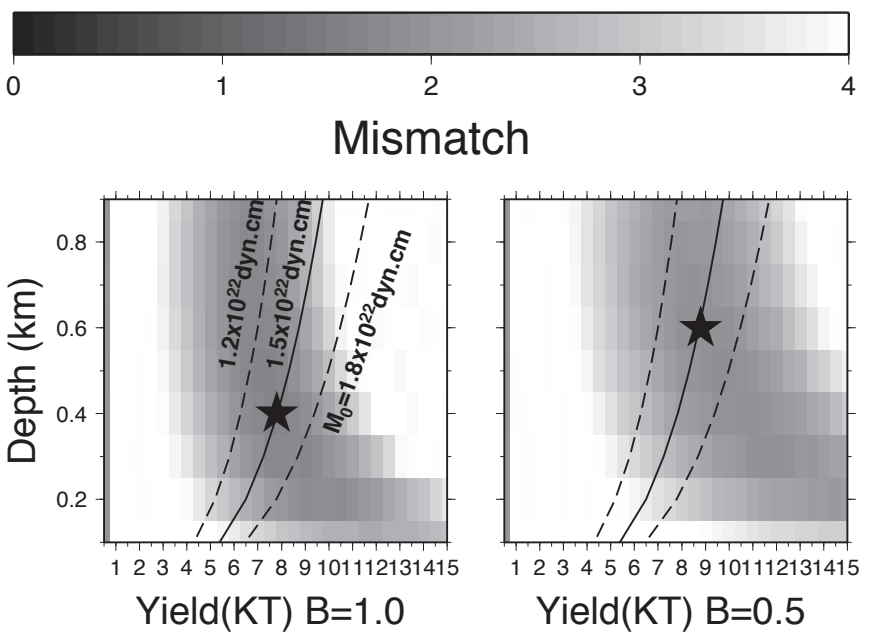

Figure 9. Same as Figure 7, for the second nuclear test.

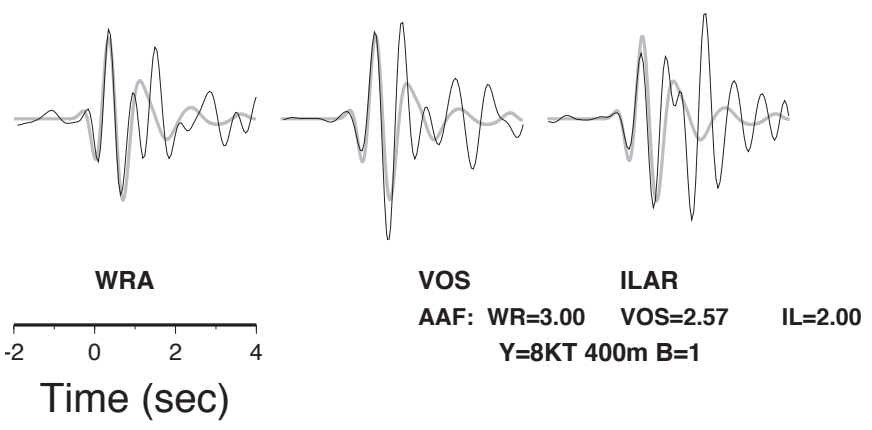

A Figure 10. Same as Figure 8, for the second nuclear test.

Burdick, L. J., T. Wallace, and T. Lay (1984). Modeling near-field and teleseismic observations from the Amchitka test site. Journal of Geophysical Research 89 (B6), 4,373-4,388.

Butler, R., and L. Ruff (1980). Teleseismic short-period amplitudes: Source and receiver variations. Bulletin of the Seismological Society of America 70 (3), 831-850.

Cho, K. H., R. B. Herrmann, C. J. Ammon, and K. Lee (2007). Imaging the upper crust of the Korean Peninsula by surface-wave tomography. Bulletin of the Seismological Society of America 97, 198-207.

Clouser, R. H., and C. A. Langston (1995). Modeling P-Rg conversions from isolated topographic features near the NORESS array. Bulletin of the Seismological Society of America 85, 859-873.

Douglas, A., and P. D. Marshall (1996). Seismic source size and yield for nuclear explosions. In Monitoring a Comprehensive Test Ban Treaty, ed. E. S. Husebye and A. M. Dainty, 309-353. Dordrecht and Boston: Kluwer Academic Publishers.

Helmberger, D. V. (1983). Theory and application of synthetic seismograms. In Earthquakes: Observation, Theory and Interpretation, ed. H. Kanamori, 174-222. Bologna, Italy: Società Italiana di Fisica. In English.

Helmberger, D. V., and D. Hadley (1981). Seismic source functions and attenuation from local and teleseismic observations of the NTS events JORUM and HANDLEY. Bulletin of the Seismological Society of America 71 (1), 51-67.

Helmberger, D. V., and B. Woods (1996). Regional source parameters, seismic energy, and discrimination. In Monitoring a Comprehensive Test Ban Treaty, ed. E. S. Husebye and A. M. Dainty, 365-383. Dordrecht and Boston: Kluwer Academic Publishers

Herrmann, R. B., Y. Jeon, W. Walter, and M. Pasyanos (2005). Seismic source and path calibration in the Korean Peninsula, Yellow Sea and Northeast China. In 27th Seismic Research Review: Ground- 

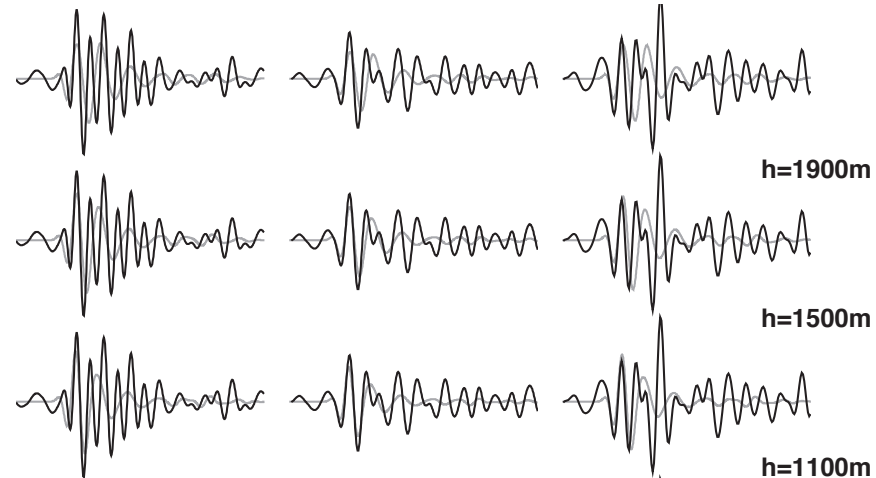

$h=1100 m$
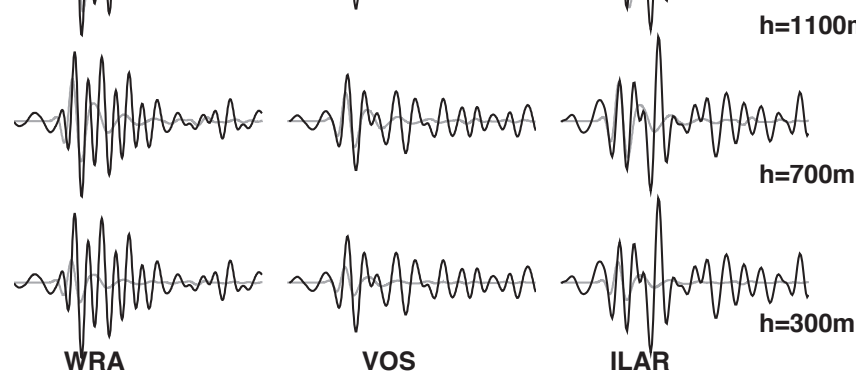

vos

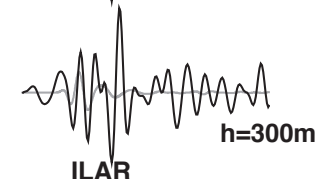

AAF: $W R=0$.

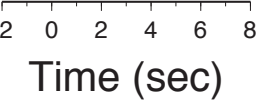

$B=1$

$\Delta$ Figure 11. Sensitivity test from comparison of observed (black) and synthetic (gray) seismograms for different depths. $B$ $=1$ and appropriate AAF is adopted in generating the synthetic seismograms. With larger depth $(\geq 1300 \mathrm{~m})$, the synthetic $P$ wave does not match observation well, and too small depth $(300 \mathrm{~m})$ typically leads to too weak $P$ wave.

Based Nuclear Explosion Monitoring Technologies, Technical Report LA-UR-06-5471, Vol. 1, pp. 60-70.

Koper, K. D., R. B. Herrmann, and H. M. Benz (2008). Overview of open seismic data from the North Korean event of 9 October 2006. Seismological Research Letters 79 (2), 178-185.

Lynnes, C. S., and T. Lay (1988). Analysis of amplitude and travel time anomalies for short-period $P$-waves from NTS explosions. Geophysical Journal of the Royal Astronomical Society 92,431-443.

Mueller, R., and J. Murphy (1971). Seismic characteristics of underground nuclear detonations, Part I: Seismic spectrum scaling. Bulletin of the Seismological Society of America 61, 1,675-1,692.
Murphy, J. (1977). Seismic source functions and magnitude determinations for underground nuclear detonations. Bulletin of the Seismological Society of America 67, 135-158.

Ni, S., A. Pitarka, and D. V. Helmberger (2008). Short-period synthetics for 3D models, numerical vs. analytical. Seismological Research Letters 79 (2), 298.

Pitarka, A., D. V. Helmberger, and S. Ni (2008). Analysis and simulation of three-dimensional scattering due to heterogeneous crustal structure and surface topography on regional phases: magnitude and discrimination. In 29th Monitoring Research Review: GroundBased Nuclear Explosion Monitoring Technologies , 205-213.

Richards, P. G., and W.-Y. Kim (2007a). Seismic signature. Nature Physics 3, 4.

Richards, P. G., and W.-Y. Kim (2007b). North Korean nuclear test: Seismic discrimination at low yield. Eos, Transactions, American Geophysical Union 88 (14), 158.

Saikia, C. K., D. V. Helmberger, R. J. Stead, and B. B. Woods (2001). Effects of source RDP models and near-source propagation: Implication for seismic yield estimation. Pure and Applied Geophysics 158, 2,173-2,216.

Tan, Y., and D. V. Helmberger (2007). A new method for determining small earthquake source parameters using short-period $P$ waves. Bulletin of the Seismological Society of America 97 (4), 1,176-1,195.

Walter W. R., E. Matzel, M. E. Pasyanos D. B. Harris, R. Gok R, et al. (2007). Empirical observations of earthquake explosion discrimination using $P / S$ ratios and implications for the sources of explosion $S$-waves. Proc. 29th Monitoring Research Review, Denver, Colo., Tech. Rep. LA-UR-07-5613. pp. 684-693.

Yang, X., I. Bondar, K. McLaughlin, and R. North (2001). Source specific station corrections for regional phases at Fennoscandian stations, Pure and Applied Geophysics 158, 35-57.

Zhu, L., and D. V. Helmberger (1996). Advancement of source retrieval from broadband regional seismograms. Bulletin of the Seismological Society of America 86, 1,634-1,641.

Zhu, L., Y. Tan, D. V. Helmberger, and C. K. Saikia (2006). Calibration of the Tibetan Plateau using regional seismic waveforms. Pure and Applied Geophysics; doi:10,1007/s00024-006-0073-7, 1193-1213.

URS Corporation 566 El Dorado Street Pasadena, California 91101-2560 U.S.A. stoneustc@gmail.com

(S. N.) 